MITA (P) 134/08/2002

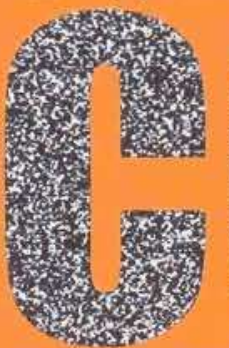

FREE COPY FOR QUALIFIED READERS
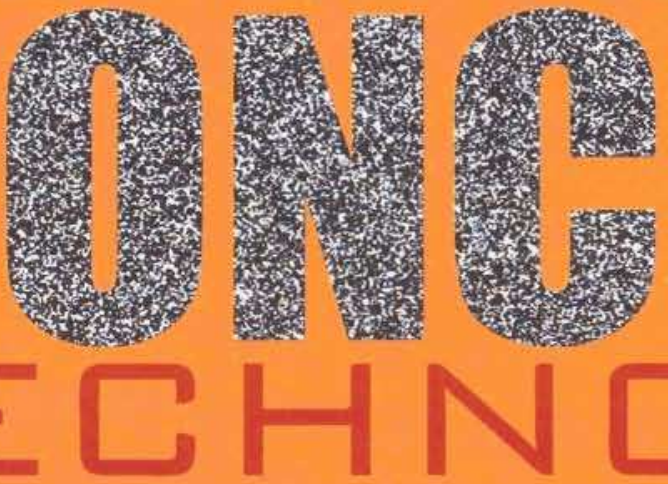
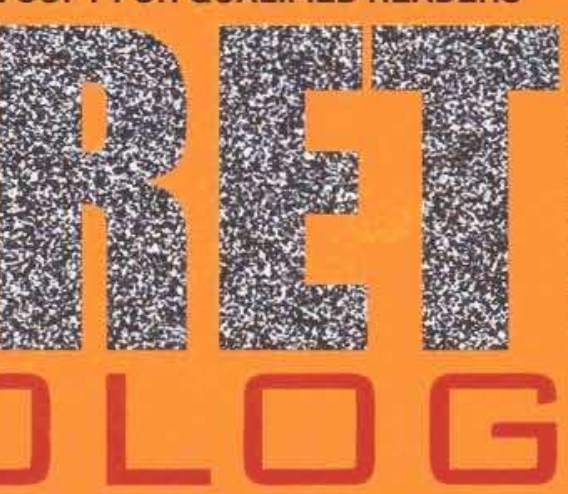
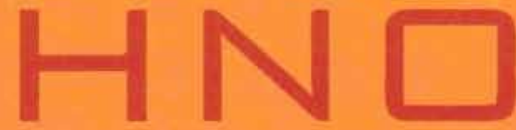

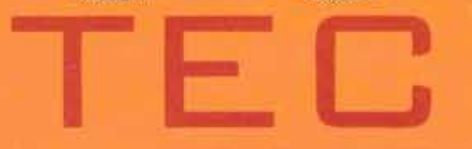

STRUCT
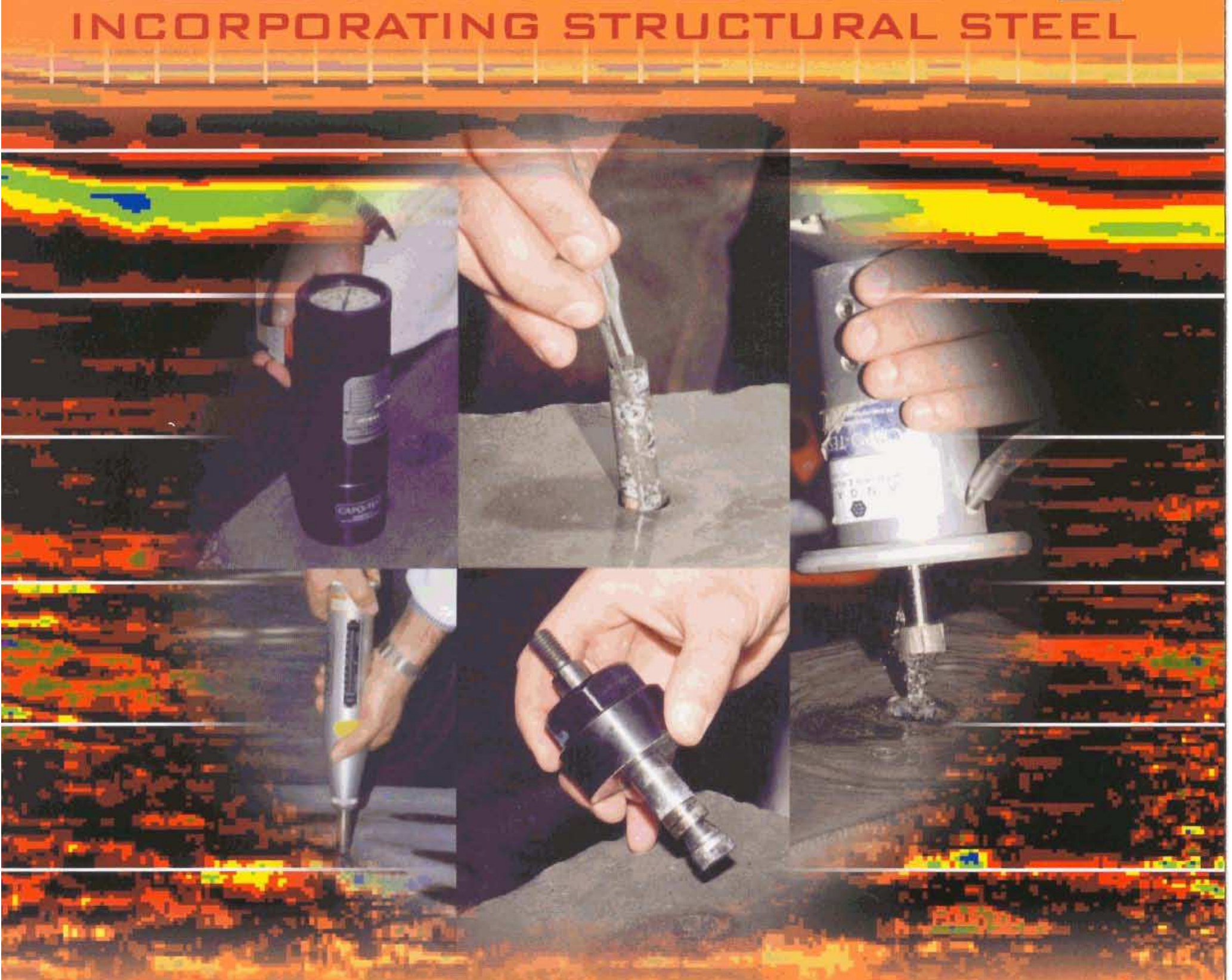

COVER STORY: Concrete Testing

Radar as nondestructive testing tool for concrete Non-destructive Tests On Concrete

Cubelnfo

Controls equipment for Mapei France lab

CONCRETE FEATURE

Developments from CSIRO
CONCRETE TECHNOLOGY

ConstructiVision

ConcreteKiosk

Termacol

Recycled aggregates for precast concrete

STRUCTURAL STEEL

Serdang Hospital in Kuala Lumpur Interview with MSSA President Profile on SSSS President 


\section{tests on}

\section{concrete}

by Miguel C. S. Nepomuceno, Lecturer, University of Beira Interior, Portugal and

Sérgio M. R. Lopes, Assistant Professor, University of Coimbra, Portugal
Concrete compressive strength of standard samples curing under standard conditions are of utmost importance for quality control of concrete as it is produced. However, those values can only be accepted as indicating the 'potential strength' of concrete and may differ from the actual in-situ concrete compressive strength.

The knowledge, as close as possible, of the in-situ concrete compressive strength is, in some situations, necessary in order to estimate, for instance, the time when precast concrete members can be moved and transported, the time of prestressing, removal of moulds or propping, etc. 
Non-destructive tests (NDT) have been increasingly used in the last few decades for the assessment of in-situ quality and integrity of concrete elements, especially for estimation of in-situ concrete compressive strength. National standards are available in a number of countries, notably in the UK and USA, detailing procedures for the most firmly established testing methods. It is important to mention that procedures from different national standards present small differences.

Non-destructive tests present some significant advantages such as speediness of operation, immediate availability of results, less costs and, above all, less damage for concrete elements under test. The NDT methods are specially designed for estimation of the in-situ concrete compressive strength and do not allow a direct quantitative measurement of such property. Therefore, it would be necessary to develop and use empirical correlations. Such correlations introduce uncertainties on the results, which represent the main disadvantage of these tests when compared to those methods based on drilled cores. In spite of that, when based on firm correlations, the accuracy of such estimations improves significantly and it could overcome such drawbacks [3].

The NDT techniques actually available vary significantly in terms of accuracy, degree of destruction caused to concrete elements, speed of test, immediacy of results and costs involved. Those methods have been traditionally used on normal strength concrete. Although, since high strength concrete is being increasingly used all over the world, many research works have been developed during the last ten years to test the applicability of such methods to high strength concrete.

The use of NDT methods on normal and high strength concrete elements will be qualitatively discussed on this paper, taking as reference five different test methods, which imply the measurement of other five different properties. Such properties include the measurement of the surface hardness, ultra-sonic pulse velocity, penetration resistance, pullout force and direct tensile strength (pull-off test).

\section{Surface Hardness Test}

This type of testing has being applied to concrete since the 30 's and from the early attempts different methods and techniques have been proposed. The method proposed by the Swiss engineering Ernst Schmidt in the 40's is based on the rebound of an incident mass has been recognised as the most reliable and it is still used nowadays $[3,6]$.

The Schmidt hammer has been used with success to evaluate the surface hardness, with special evidence for such apparatus type $\mathrm{N}$, with an impact energy of 2.207 N.m (Figure I and Figure 2). Its use is covered by various national standards such as the Recommendations from British Standards BS:1881:Part 202 [4]

The surface hardness test is easy to operate, only requires a free surface, is cheap, and causes less damage than the majority of the other non destructive tests. However its use to estimate directly the in-situ compressive strength using general established correlations is not recommended by many authors [6].

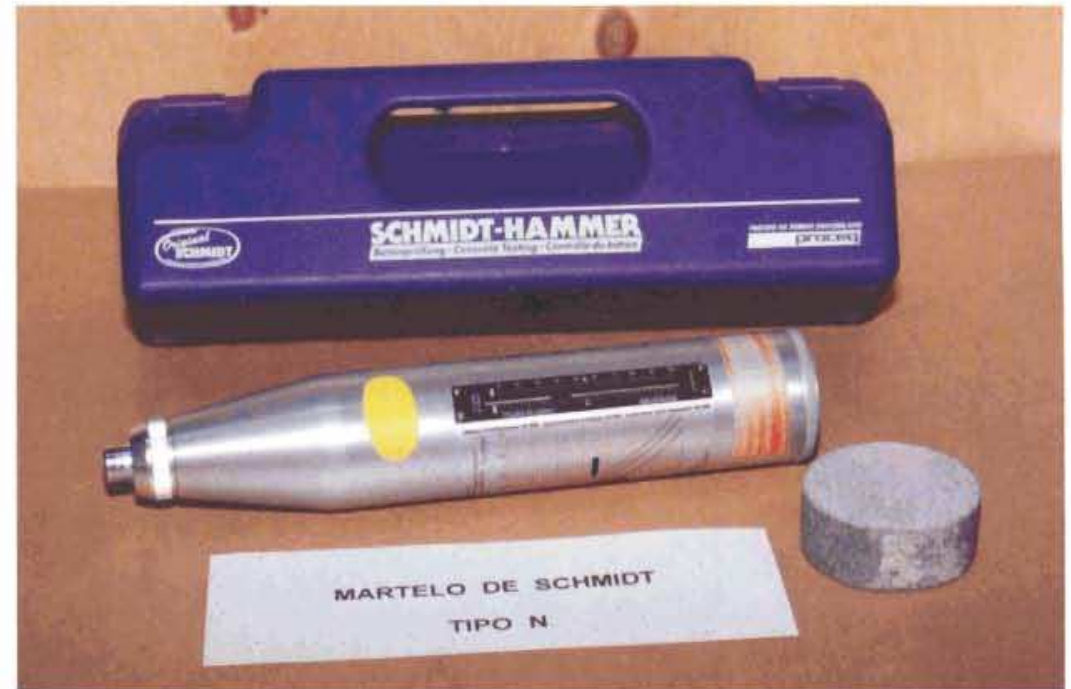

Figure 1 - Schmidt Rebound Hammer type N.

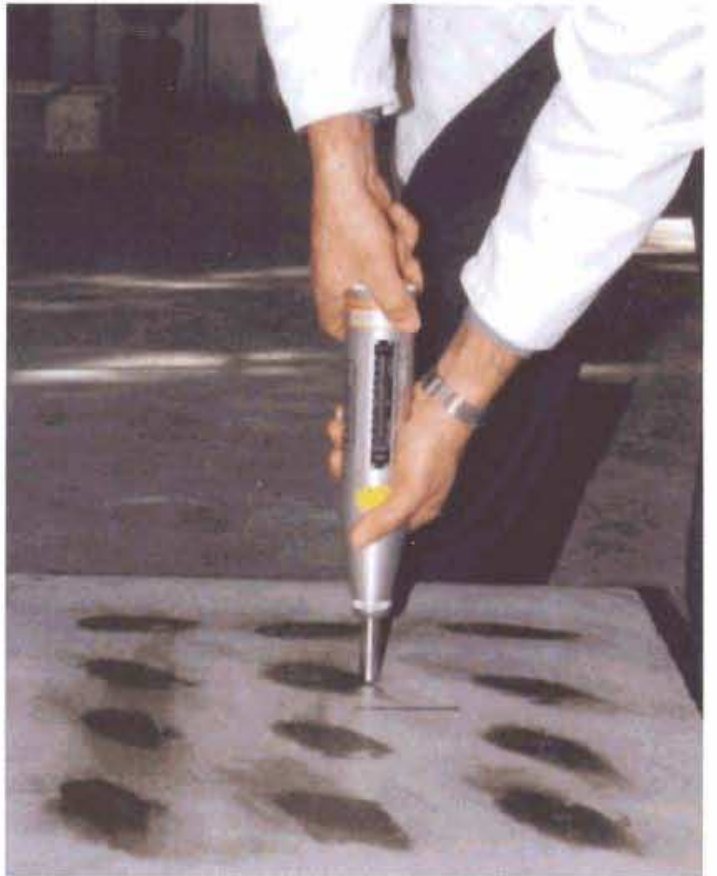

Figure 2 - Loading Schmidt Rebound Hammer.
This fact is a direct consequence of the high number of practical factors that can affect the rebound of the incident mass, due to the difficulty of taking into account the correct influence of such factors or to reproduce similar conditions as those using on calibration test.

Some professionals have pointed out that even in situations where these conditions are well reproduced in-situ and specifically developed correlations are used, the 95 percent confidence limits on the estimation of compressive strength deviate 25 percent from the mean value $[4,6]$. Under ideal laboratory conditions it is probable that this difference would be reduced to 15 percent $[4,6]$. 


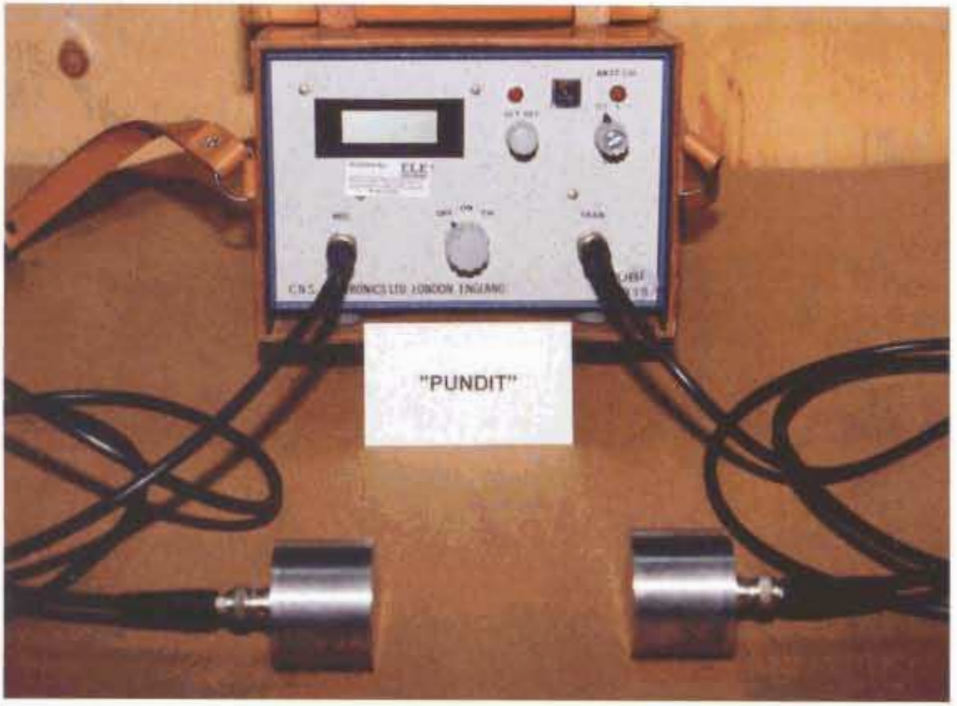

Figure 3 - Ultra-sonic Pulse Velocity Test Equipment.

The experience has shown that the surface hardness test can be very useful in situations in which correlations are not needed, for example, to monitor large surfaces for comparative analysis and localisation of critical zones, where other more reliable tests can be applied, which unfortunately causes more surface damage and are more expensive.

\section{Ultra-sonic Pulse Velocity Test}

The ultra-sonic pulse velocity test is well studied and its use is generalised worldwide. This method does not cause any damages on concrete surface and it is believed to be one of the methods that can be used to evaluate the interior mass of concrete elements [6]. One of the most generalised equipment used on concrete is the Portable Ultra-sonic Non-destructive Digital Indicating Tester (PUNDIT) with electro-acoustical transducers of natural frequency of $54 \mathrm{kHz}$ (Figure 3) [3]. Recommendations for its use can be found, for example, on British Standards Institution BS:1881:Part 203 [2]

The factors which affect the test results have been studied for many years and, in some cases, correction factors were developed to take into account, for example, the presence of reinforcement bars. The ultra-sonic pulse velocity depends on the modulus of elasticity of the material which is related to concrete compressive strength. Despite all the recognised practical advantages, the UPV test has some of the problems referred to the penetration resistance test, i. e., this test does not give a direct reading of the concrete compressive strength, and the correlations are affected by a large number of factors. There exist some correction factors, but practice has demonstrated that it introduces large uncertainties on the result, with consequences on the accuracy of the estimation value.

It has been pointed out that, even using correlations specifically developed for a given concrete under good in-situ conditions, it is unlikely that the 95 percent confidence limits for the estimation of the compressive strength are better than 20 percent of the mean value $[2,6]$. Using general correlation curves, this difference could arise to 50 percent $[2,6]$. Using specific correlation curves developed in the laboratory, such 95 percent confidence limits could deviate ro percent from the estimated mean value $[2,6]$.

Correlation between compressive strength and pulse velocity has shown exponential behaviour $[2,6,12]$, which leads to the loss of sensibility of the test for high strength concrete, i. e., a little increase on pulse velocity corresponds to a great increase on compressive strength. For this reason the applicability to high strength concrete needs to be further investigated. A first attempt was made by the authors [12] and the obtained correlation curves have shown a considerable variation on estimation of concrete compressive strength when dealing with concrete elements of compressive strength of more than $70 \mathrm{MPa}$. Probably, it is a natural consequence of exponential correlation which increases considerably at this level of strength.

As for surface hardness test, unless a specific calibration curve can be obtained, it is virtually impossible to predict the absolute strength of a mass of in-situ concrete by pulse velocity measurements $[2,6,12]$. However, this test is useful for comparative and uniformity assessments.

\section{Penetration Resistance Test}

Penetration resistance tests have been used for many years mainly supported by the Windsor Probe Test System (WPTS) and its use has been more generalised in North America [6]. USA Standards ASTM C803-90 [I] or BS:1881:Part 207 [5] have been used as reference. For normal strength

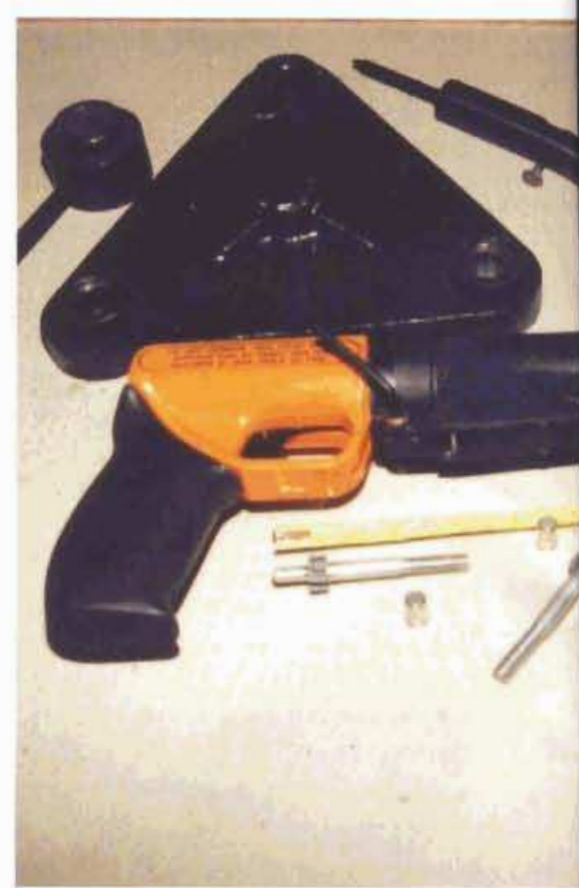

Figure 4 - Windsor Probe Test System. 
concrete the WPT system is used with silver coloured probes of hardened steel alloy with $6.35 \mathrm{~mm}$ diameter, $79.5 \mathrm{~mm}$ length, blunt conical end with a plastic guide and the standard power (Figure 4).

The WPT System causes some damages on the concrete surface and, in some circumstances its reparation can be necessary. On the other hand its application is limited by restrictions of minimum edge distances (to prevent splitting) and minimum distance between two probes (to avoid overlapping of zones of influence). This may limit the use of the technique in some situations. Usually this method is recommended for elements of large surfaces like slabs or elements of large cross sections [3].

The penetration resistance tests can be used in the situations mentioned above for comparative analysis of similar concrete elements, showing as an advantage, comparatively to the surface hardness and ultra-sonic pulse velocity tests, more accuracy on estimation of the concrete compressive strength [3].

However, the damages that this test can produce on the surface and the high cost of ammunitions and probes are the reasons why this method has not been extensively used $[9, \mathrm{IO}, \mathrm{II}]$. For this reason it is unlikely that penetration resistance replaces the surface hardness or the ultra-sonic pulse velocity tests for comparative analysis of concrete.

The traditional WPT system has shown to be limited to con crete compressive strength of less than $40 \mathrm{MPa}$ (on cylinders) $[5,9,10,11]$. However, the authors have confirmed that the measurement of penetration resistance can be extended to concrete compressive strength of at least 85 MPa (on cubes of $150 \mathrm{~mm}$ side) using a new technique supported by a new equipment named 'Alternative Firing Apparatus' [9, $\mathrm{IO}, \mathrm{II}]$. This new technique has also shown to be adequate for normal strength concrete offering the advantages of reducing the damages in comparison to the traditional WPT system $[9,10, \mathrm{II}]$. It is also important to note that the application costs of this new equipment is lower compared to the traditional WPT system. This fact may con- tribute to a more extensive application of this method.

\section{Pull-Out Test}

Pull-out Test is recognised, among the main non-destructive tests, as that which offers more accuracy on the estimation of the in-situ concrete compressive strength $[5,6]$. Recommendations for its use are provided by British Standards BS 188I: Part 207 [5].

One of the techniques used for this purpose is the CAPO-TEST System developed by 'Germann Instruments A/S' (Figures 5 to $\mathrm{II}$ ). The load is applied to the capo-insert by means of an hydraulic jack and a reaction ring of $55 \mathrm{~mm}$ inner diameter. The capo-insert ( $25 \mathrm{~mm}$ diameter ring) is placed at a depth of 25 $\mathrm{mm}$.

In the last few decades, independent analytical and experimental studies have been developed to understand how failure mechanism works during the pull-out tests. A consensus has been achieved regarding the existence of a triaxial state of stress highly non uniform on the concrete involved the capoinsert during extraction $[6,7]$. In spite of some divergence as far as
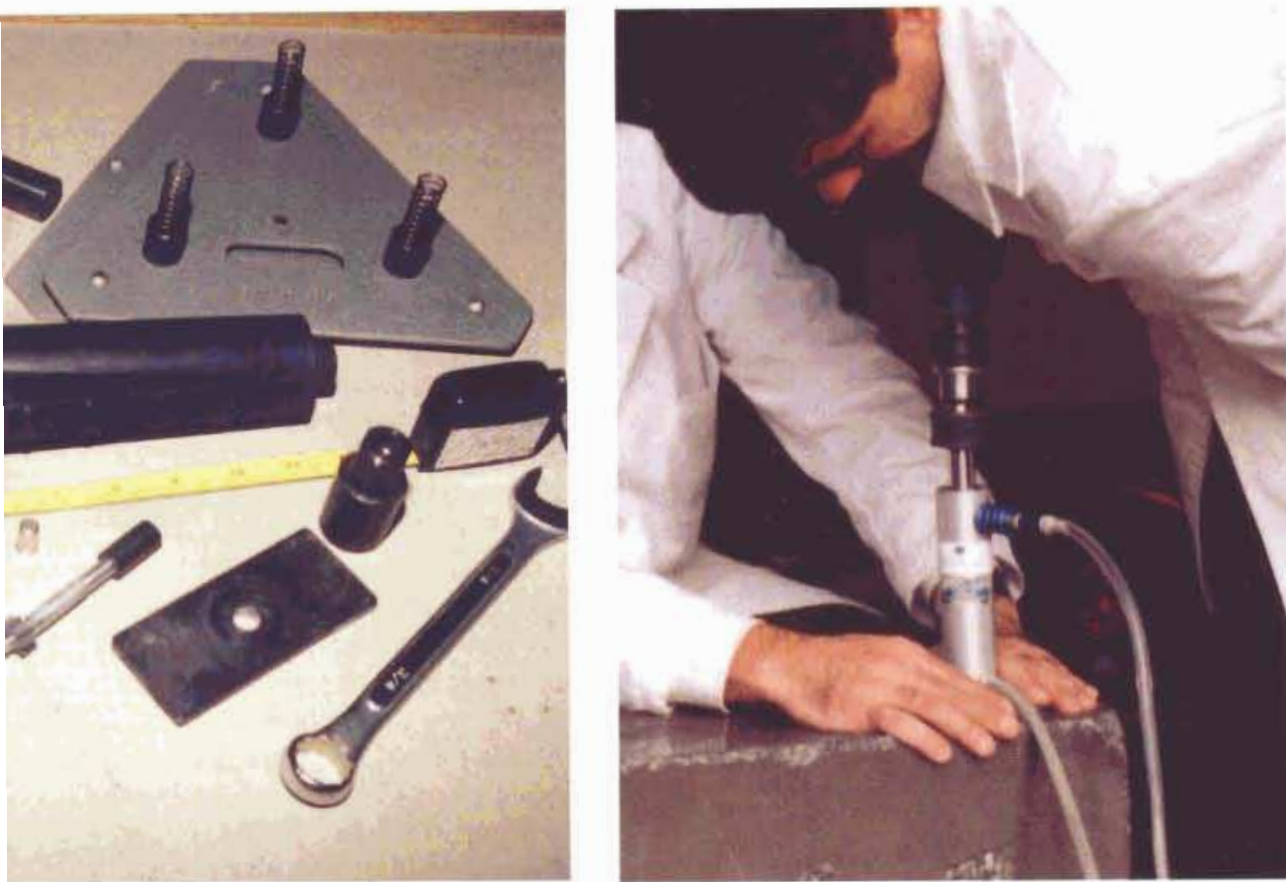

Figure 5 - Drilling a $18 \mathrm{~mm}$ centre hole with a drill unit.

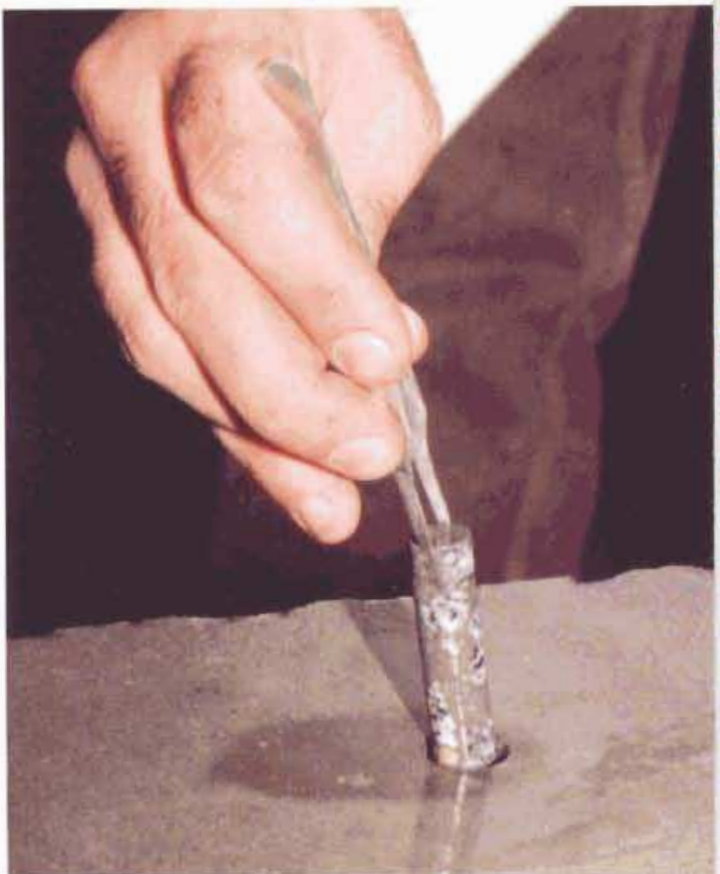

Figure 6 - Removing the drilled core in its full $65 \mathrm{~mm}$ length. 


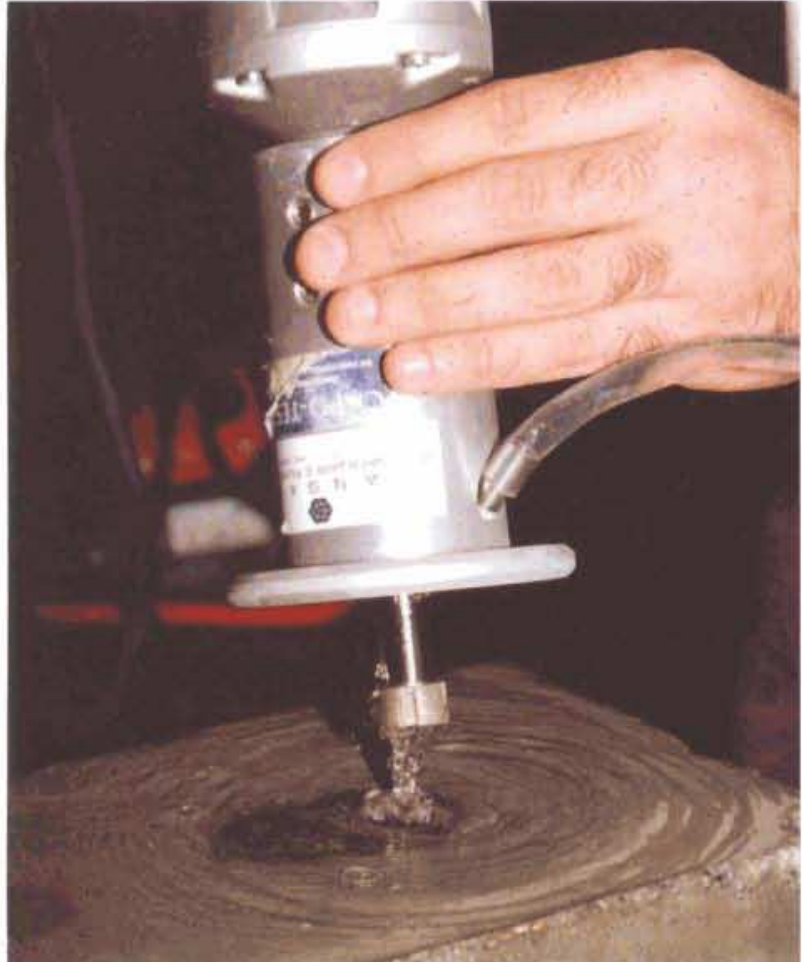

Figure 7 - Using the diamond recess router to open an inside hole at $25 \mathrm{~mm}$ depth.

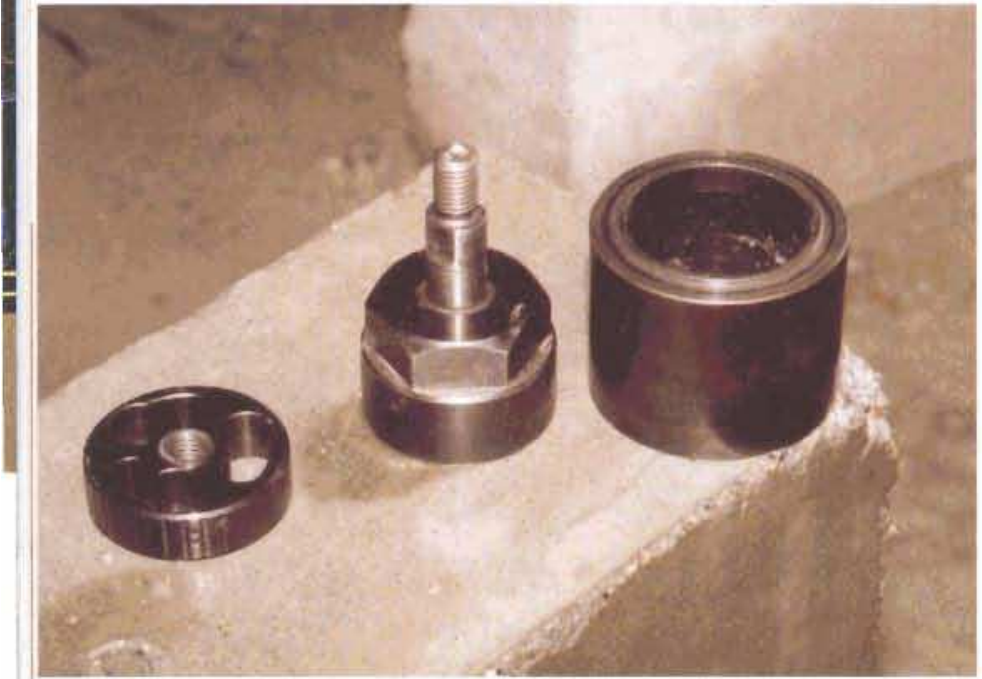

Figure 9 - Coupling and the $55 \mathrm{~mm}$ inner diameter counterpressure.

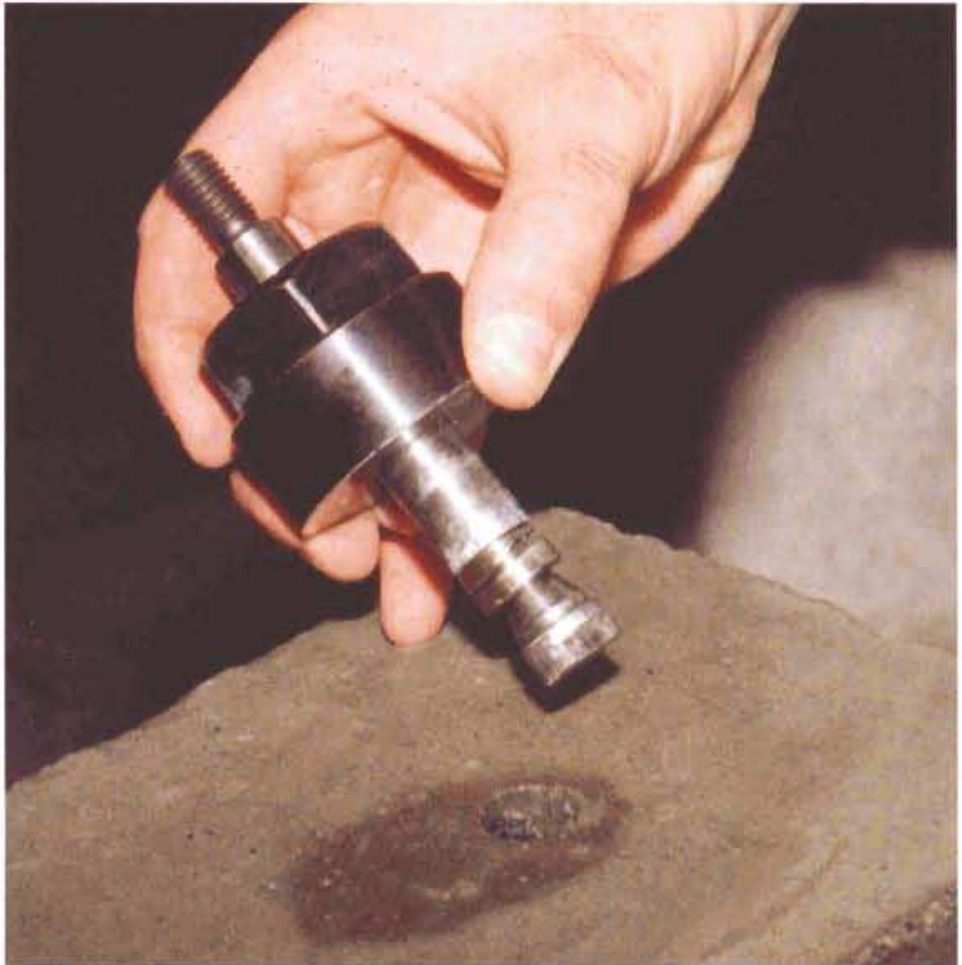

Figure 8 - The expansion unit is inserted in the hole and the capoinsert is fully expanded to $25 \mathrm{~mm}$ diameter.

methods. Examples of which are the excellent correlation curves for the compressive concrete strength versus the pull-out force; the fact that the number of factors that affect the results are considerably reduced compared to other non destructive tests; the possibility of the correlation curves to be generalised to natural aggregate classes; the cost and the procedure of this methods, which is cheap and relatively quick to operate; and finally, the fact that the results are immediately available. Its applicability has been mainly recommended in situations where a high accuracy of results is needed $[5,6,7]$.

Using specifically developed correlations to the studied concrete, the 95 percent confidence limits of in-situ compressive strength estimation in a location could be anticipated in the ro percent deviation interval from the mean value, obtained through the 4 valid readings of pull-out test $[5,6]$. Using general correlations, such as those suggested by Loktest and Capo-test manufacturers, that interval would probably be widened to 20 percent $[5,6]$.
The Lok-test and Capo-test were developed in Denmark and have the same test geometry and are a reference test in Europe.

Both tests have an apex angle of $62^{\circ}$ and measure the force with which a $25 \mathrm{~mm}$ diameter disc placed at $25 \mathrm{~mm}$ depth is extracted from concrete by means of an hydraulic jack reacting over bearing ring of $55 \mathrm{~mm}$ interior diameter, placed on concrete surface.

The pull-out test probes can be introduced in fresh concrete applying the lok-test system, which requires the previous test planning. The capo-test system can be alternatively used in hardened concrete at any time, through the opening and wideness of an inside hole, where an expansive ring with the same diameter at the same depth as the lok-test system is placed

The capo-test system produces some surface damages on concrete elements and, in some circumstances, its reparation may be needed. The lok-test system may be optionally applied with or without full extraction of the insert. The second option does not create visible surface damages. The 


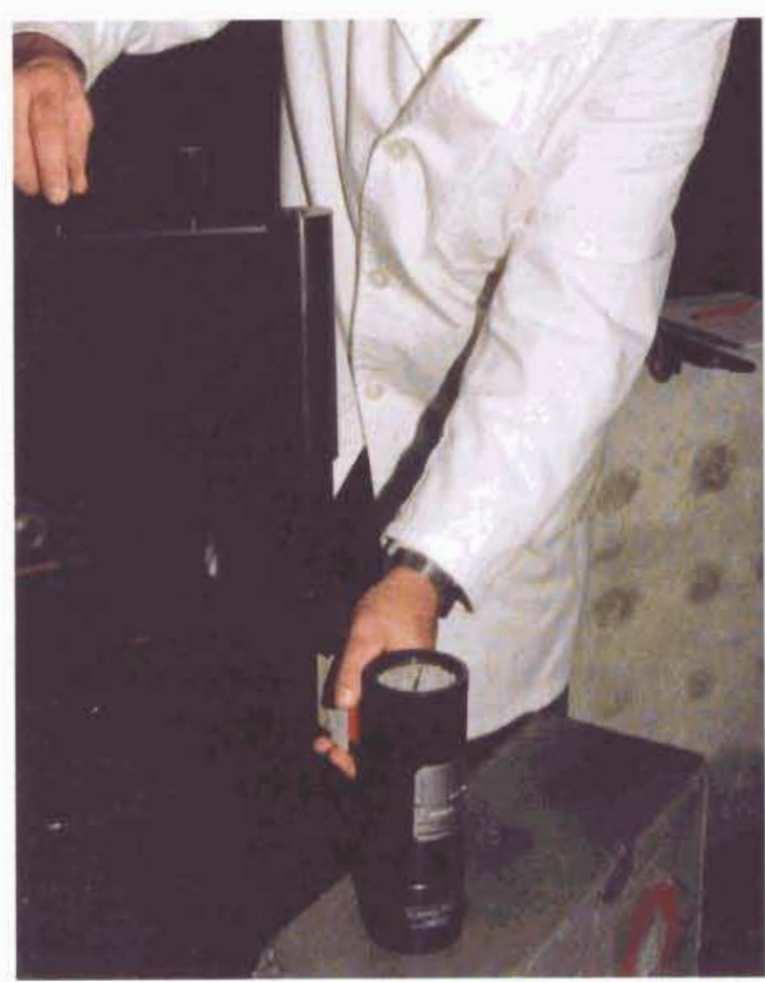

Figure 10 - Loading the instrument by turning the loading handle.

minimum distances usually required for locations are limiting for small elements as for penetration resistance tests.

\section{Pull-Off Test}

The pull-off tests enable the determination of direct tensile strength in-situ (Figures $\mathrm{I}_{2}$ and $\mathrm{I}_{3}$ ). The possibility of using this method with partial coring enables the measurement of such property at different depths. For this test method, recommendations are available on British Standards BS I88I: Part 207 [5]. Figures 15 and 16 show a technique developed by ' Germann Instruments A/S' to support this method and called BOND- TEST System. This system includes a portable hand operated hydraulic jack, a circular steel disk with $75 \mathrm{~mm}$ diameter and $30 \mathrm{~mm}$ thickness and the equipment for preparation of surfaces and partial coring of concrete.

The possibility of establishing, for a given test equipment and a given concrete, a correlation between the pulloff test and the compressive strength has shown to be useful for estimation of the in-situ concrete compressive strength $[5,6]$. In spite of other practical factors that can affect the results, one fact that should not be forgotten is that pull- off test results on the surface differ from those using partial coring and that the depth of partial coring should be also taken into account $[5,6]$.

A research work carried out by the authors has shown that the applicability of pull-out tests, using the Bondtest system, is limited to concrete elements of compressive strength of no more then $45 \mathrm{MPa}$ (on cubes of $150 \mathrm{~mm}$ side) [1o]. It was also found out that the use of partial coring causes considerable surface damages and needs a considerable time to operate. However, partial coring enables the evaluation of concrete strength at deeper layers

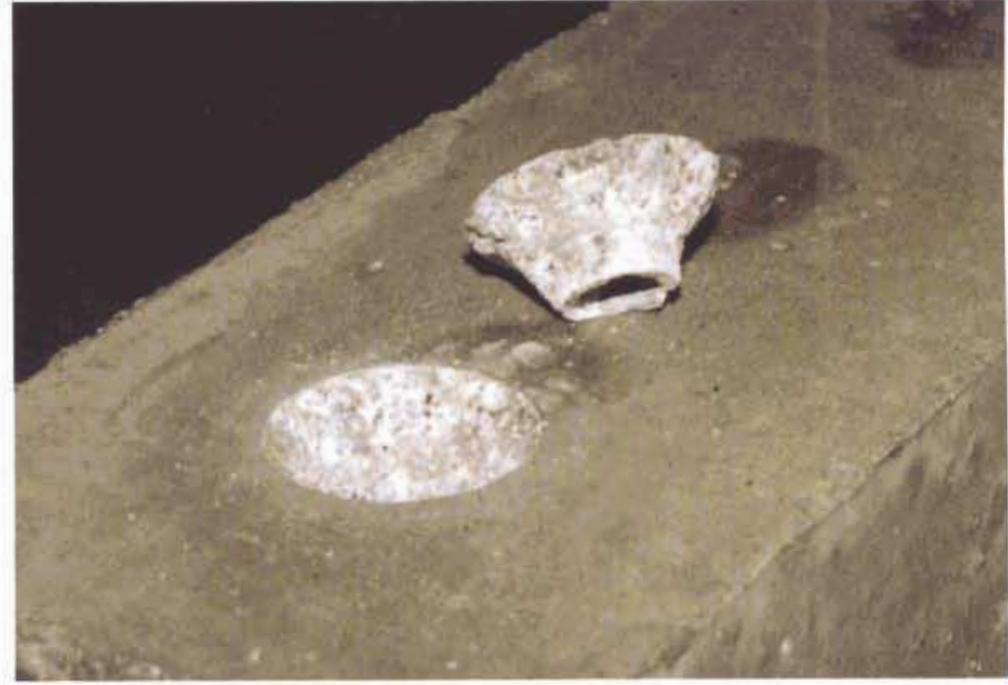

Figure 11 - Failure type is observed for validation of result.

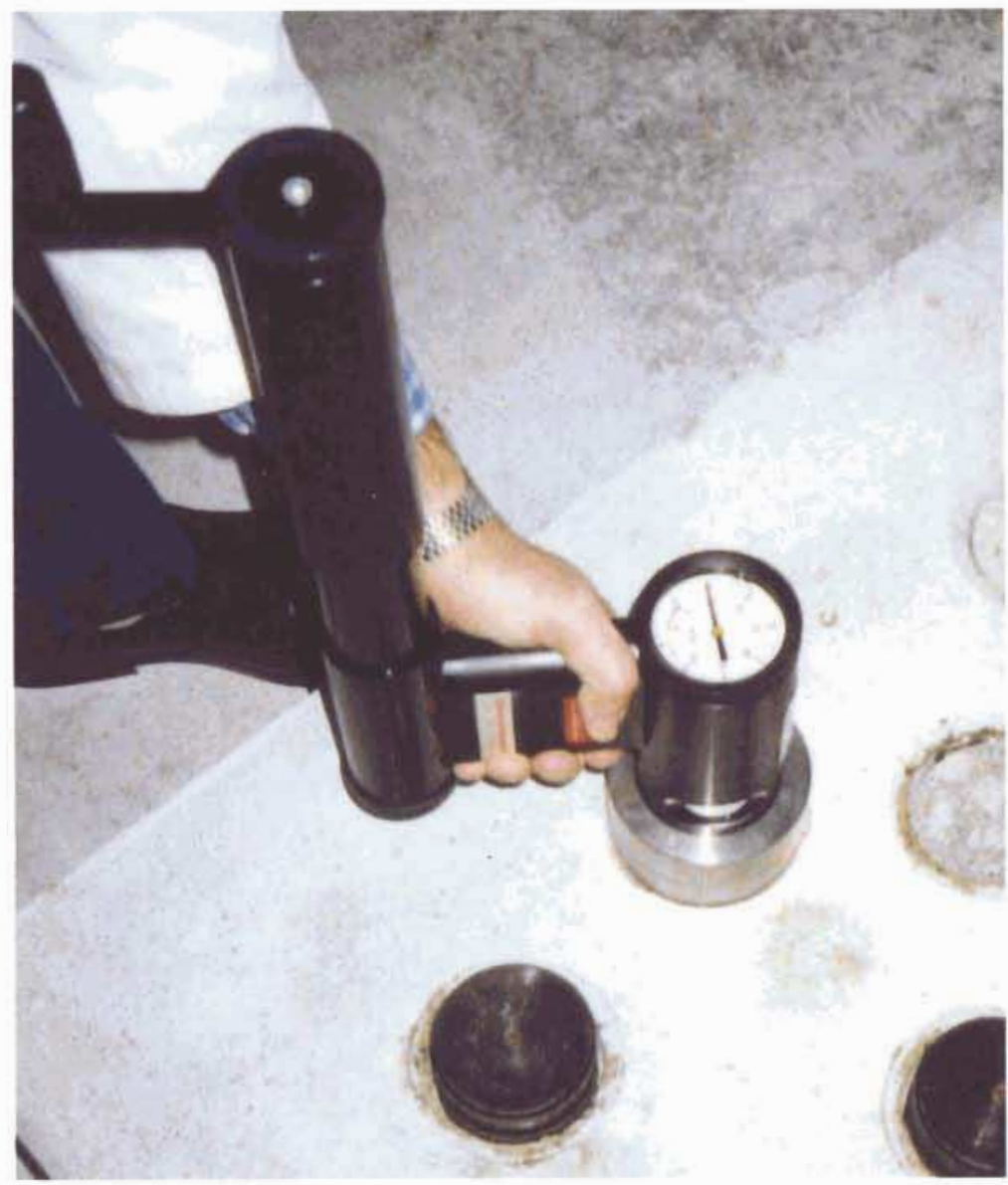

Figure 12 - Loading the instrument 


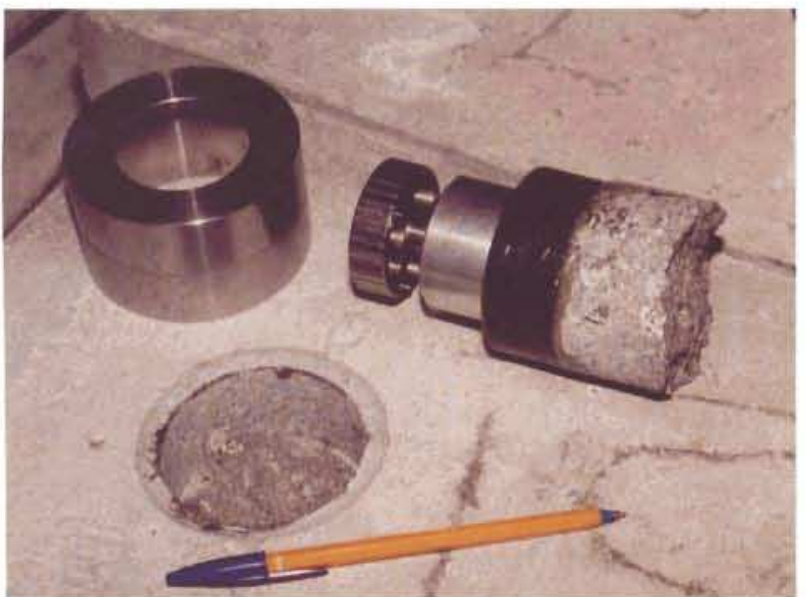

Figure 13 - Failure type is observed for validation of result. laboratory conditions and using 6 valid readings in each location, the British Standards BS 1881: Part 207 [5] points out that the 95 percent confidence limits for the estimation of compressive strength the values could vary ( 15 percent from the mean value).

\section{About the authors}

Miguel Costa Santos Nepomuceno is a Lecturer at the University of Beira Interior, Portugal . He has a First Degree in Civil Engineering from the University of Beira Interior, 1994; MSc, Concrete Materials, University of Beira Interior, 1999; Ph.D Student; He is a Member of the Portuguese Association of Engineers since 1992. His area of specialisation is in Concrete Materials.

Sérgio Manuel Rodrigues Lopes is an Assistant Professor, University of Coimbra, Portugal. He has a First Degree in Civil En- gineering from the University of Coimbra, 1984; MSc in Structural Engineering, Technical University of Lisbon, 1988; Ph.D from the University of Leeds, England, U.K., 1991. He is Senior Member of the Portuguese Association of Engineers, 1992, was Nominated for Ferry Borges Prize as one of best papers in International Journals, 1999. His area of specialisation is in Structural Concrete. He is a Member of FIP Commission Io Management, maintenance, and strengthening of concrete structures; Member of Portuguese Mirror groups for the normalization of both European Structural Concrete Code, Eurocode 2, and of European Concrete Standard, ENV206; and Individual member of ACI, Portuguese Structural Concrete Group (Portuguese Charter of Fib) and Portuguese Group of Structural Engineering (Portuguese Charter of IABSE).

\section{References:}

[I] ASTM C803-90 - Standard Test Method for Penetration Resistance of Hardened Concrete, Philadelphia, American Society for Testing and Materials, 1990.

[2] British Standard BS 188I :Part 203: 1986 - Testing Concrete: Recommendations for Measurement of Velocity of Ultrasonic Pulses in Concrete, London, British Standard Institution.

[3] British Standard BS 188r: Part 201: 1986 - Testing Concrete: Guide to the Use of Non-destructive Methods of Test for Hardened Concrete, London, British Standards Institution.

[4] British Standard BS 1881: Part 202: 1986 - Testing Concrete: Recommendations for Surface Hardness Testing by Rebound Hammer, London, British Standards Institution.

[5] British Standard BS 1881: Part 207: 1992 - Testing Concrete. Recommendations for the Assessment of Concrete Strength by Near-to-surface Tests, London, British Standards Institution.

[6] BUNGEY, J. H.; MILI.ARD, S. G. - Testing of Concrete in Structures, 3. ${ }^{\text {a }}$ ed., London, Chapman \& Hall, 1996.

[7] CARINO, J. Nicholas - Pullout Test, in "Handbook on Non- destructive Testing of Concrete", Florida (EUA), CRC Press Inc., 1991, p. 39-82.

[8] KRENCHEL, H.; PETERSEN, C. G.- In-situ Pullout Testing with Lok-test. Ten Years' Experience. "International Conference on In situ/ Non-destructive Testing of Concrete», Ottawa, 2-5 Oct.1984.

[9] LOPES, Sérgio; NEPOMUCENO, Miguel - A Comparative Study of Penetration Resistance Apparatus on Concrete, in "Proceedings of ICCE/4", Hawaii, David Hui Edition, Jul. 1997, p. 615-616.

[10] LOPES, Sérgio; NEPOMUCENO, Miguel - Evaluation of In-place Concrete Strength by Nearto-surface Tests. "12th European Ready Mixed Concrete Congress", Lisbon, APEB, June 1998, p. $338-347$.

[II] LOPES, Sérgio; NEPOMUCENO, Miguel - High Strength Concrete: Penetration Resistance Tests on High Strength Concrete, in «First International Conference on High Strength Concrete, July 13-18, 1997`, ASCE, USA, 1999, ISBN 0-7844-0419- 4, p. 425-433.

[12] LOPES, Sérgio; NEPOMUCENO, Miguel - Non-Destructive Tests on Normal and High Strength Concrete, in aProceedings of 26 th Conference on Our World in Concrete \& Structures, August 27-28, 2001, volume XX (2001)», Singapore, ISBN 981-04-2513-9, p. 53-67. 